\title{
CUSTO OPERACIONAL DE DUAS TÉCNICAS DE COLHEITA DE URINA CULTURA BACTERIOLOGICA EM MULHERES NUM HOSPITAL ESCOLA
}

\author{
Maria Helena Pessini de Oliveira * \\ Vera Heloisa Pileggi Vinha ** \\ Edna Musse de Van Grieken ***
}

$\operatorname{ReBEn} / 03$

OLIVEIRA, M.H.P. e Colaboradoras - Custo Operacional de duas Técnicas de Colheita de Urina Cultura Bacteriológica em Mulheres num Hospital Escola. Rev. Bras. Enf.: RS, 36: 20-24 , 1983.

Considerando que o exame de urina para cultura bacteriológica é importante para estabelecer o diagnóstico de infeç̧ão urinária e que várias são as tećnicas empregadas variando desde a colheita pura e simples até a punção supra-púbica, fez-se um estudo comparativo entre duas técnicas - higiene íntima feita pela própria paciente e a técnica asséptica feita por um profissional de enfermagem, sob o ponto de vista microbiológico e custo operacional.

\section{INTRODUÇÃO:}

O exame bacteriológico da urina é indispensável para que se possa afirmar com segurança a presença de infecção no trato urinário. $\left({ }^{1} .^{5}\right)$

As técnicas de colheita de urina para cultura bacteriológica em mulheres são as mais variadas possíveis podendo da colheita pura e simples sem maiores cuidados higiênicos, até a punção supra-púbica $\left({ }^{2}\right)$.

De u m modo geral os autores preocupam-se em estudar ou estabelecer técnicas que satisfaçam apenas do ponto de vista microbiolǵico, uma vez que a presença de resultado duvidoso implica na repetição de novo exame bem como tratamento desnecessário para o paciente $\left({ }^{5,3,4}\right)$.

Dado a isso grandes são as divergências de técnicas empregadas em hospitais, ambulatórios e laboratórias $\left({ }^{10,11}\right)$. Entretanto, se faz necessário a escolha ou a opção por uma técnica que satisfaça do ponto de vista microbiólógico e econômico.

Para isso, fez-se um estudo comparativo entre duas técnicas de colheita de urina para cultura bacteriológica em mulheres, visando o custo operacional e aspectos microbiológicos.

\section{MATERIAL E MÉTODO:}

Foram incluídas no trabalho 50 mulheres entre 10 a 70 anos de idade, matriculadas no Hospital das Clínicas da Faculdade de Medicina de Ribeirão Preto -USP, portadoras de um pedido de exame de urina para cultura bacteriológica, residentes na cidade de Ribeirão Preto e cidades circunvizinhas, independente das condições e grau de escolaridade.

* Prof. Assistente da Escola de Enfermagem de Ribeurão Preto - USP.

* * Prof. Assistente-Doutor da Escola de Enfermagem de Ribeirão Preto - USP.

** Enfermeira-chefe da Secção de Atendimento Integrado do Ambulatório Central do $\mathrm{H}$. C. - F. M. R. P. - USP. 
OLIVEIRA, M.H.P. e Colaboradoras - Custo Operacional de duas Técnicas de Colheitas de Urina Cultura Bacteriológica em Mulheres num Hospital Escola. REv. Bras. Enf.:RS, 36: 20-24 , 1983.

As mulheres submeteram-se a duas técnicas de colheita de urina para cultura bacteriológica em 2 dias subseqüentes.

- No primeiro dia faziam a auto-higiene dos genitais com água e sabão, como o fazem no domicúlio, porém com maior rigor. A seguir a própria paciente colhia o jato médio de urina em tubo esterilizado (técnica I).

- No segundo dia a mesma paciente submetia-se a técnica asséptica feita exclusivamente por um profissional de enfermagem, utilizando como antisséptico o sterylderme e soro fisiológico. Colhia-se o jato médio da urina em recipiente esterilizado. (técnica II).

Levantou-se o custo operacional de cada técnica que incluia:

- montagem do ambiente, materiais permanentes e de consumo, e o tempo gasto pelo funcionário.

Todo o cuidado com a conservação, transporte e a semeadura foi tomado para assegurar resultados fiéis. Nenhuma urina foi semeada depois de 2 horas de colhida e todas foram conservadas numa temperatura de 0 ? a $4^{\text {? }}$ c $\left({ }^{6,8,9}\right)$.

\section{RESULTADOS E DISCUSSÃO:}

\section{1 - Análise Microbiológica}

A análise microbiológica quantitativa das uroculturas agrupadas segundo os conceitos negativo (até $1.000 \mathrm{col} / \mathrm{ml})$; duvidosos $(>1.000$ até $100.000 \mathrm{col} / \mathrm{ml})$ e positivos $(>100.000 \mathrm{col} / \mathrm{ml})$, apre-

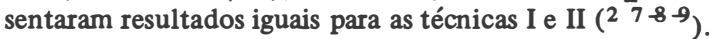

Do ponto de vista microbiológico as uroculturas apresentaram a mesma eficácia em ambas as técnicas. O resultado negativo foi da ordem de $84 \%$ para a técnica I, $86 \%$ para a técnica II. Os resultados positivos foi da ordem de $8 \%$ para as técnicas I e II. Os duvidosos tiveram os seguintes percentuais, técnica I $8 \%$ e técnica II $6 \%$.

\section{2 - Custo Operacional}

Quanto ao custo das duas técnicas, a técnica I é sobre todos os aspectos mais eficiente, portanto menos onerosa que a técnica II.

Quanto ao tempo gasto para a execução de ambas técnicas (tabela 1), observa-se os menores valores de tempo para a técnica I com 5 a 10 minutos (82\%) seguidas de 10 a 15 minutos (14\%). Para a técnica II foram 15 a 20 minutos $(56 \%$ e 20 a 25 minutos (20\%). Portanto, a média de tempo gasto para a técnica II foi de 8,8 minutos e para a técnica UU 19,8 minutos. Levando-se em conta um laboratório ou um ambulatório de alto fluxo, a técnica I é altamente vantajosa, ganhando-se em tempo e pessoal, (Tabela 1).

Na tabela 2 encontramos o material necessário à montagem do ambiente para a execução de ambas as técnicas. Considerando-se que no hospital já existia o banheiro, estimou-se qual o material permanente necessário. Assim para a técnica I o orçamento foi de $\mathrm{Cr} \$ 30.759,00$ e para a técnica II Cr\$ $77.250,00$ (fevereiro 1982), portanto esta é $151,14 \%$ mais onerosa. (Tabela 2).

A tabela 3 relaciona os materiais necessários para a execução de ambas as técnicas e seus valores unitários e totais, orçando para a técnica I Cr $\$ 168,00$ e em $\operatorname{Cr} \$ 4.653,75$ para a técnica II. (Tabela 3).

E de se considerar, porém, que o material relacionado par a a técnica II inclui alguns instrumentos como cuba rim, cuba redonda, e pinça Pean, não considerados como reutilizáveis, desde que seja num ambiente onde são necessários para outras atividades. Na realidade, para nossos cálculos, utilizamos, apenas sabão neutro $(\mathrm{Cr} \$ 1,00)$ na técnica I e sterylderme, soro fisiológico, gazes e algodão (Cr\$ 37,45) para a técnica II, que são materiais de consumo. Com a inclusão das luvas, que é indispensável na realização da técnica II, o custo eleva-se para Cr\$97,45. Um par de luvas resiste em média 2 a 3 autoclavagens. Portanto a técnica II é mais onerosa que a técnica I, 9.645\%.

A média de colheita de urina bacteriológica no Hospital das Clínicas é de 25 por dia. Portanto, gastar-se-ia Cr $\$ 25,00$ apenas de sabão neutro (um sabão neutro dá para 50 pacientes), e para a técnica II o gasto seria de $\operatorname{Cr} \$ 2.436,25$ - sterylderme, soro fisiológico, gaze, algodão e luva, isto considerando apenas material de consumo.

A estrapolação destes dados para a atividade de um ano, considerando-se como média 25 colheitas de urina por dia corresponderia aproximadamente 6.000 coletas anuais, que pela técnica I custariam Cr $\$ 6.000,00$ ao passo que pela técnica II seria Cr $\$ 584.700,00$ (somente materiais gastos sem atentar para o pessoal empregado, desgastes de material e outros. 
OLIVEIRA, M.H.P. e Colaboradoras - Custo Operacional de duas Técnicas de Colheita de Urina Cultura Bacteriológica em Mulheres num Hospital Escola. Rev. Bras. Enf.: RS, 36: 20-24 , 1983.

$\mathrm{Na}$ tabela 4 mostra o tempo gasto pelo profissional (um auxiliar de enfermagem), para executar cada uma das técnicas e seus correspondentes em cruzeiros. A técnica II foi $125 \%$ mais onerosa que a técnica I. (tabela 4).

$\mathrm{Na}$ tabela 5 estão os tempos e os valores em cruzeiros gastos pelo profissional, no caso um atendente, para preparar o pacote de material necessário a realização de ambas as técnicas, portanto a técnica II é $1.363,77 \%$ mais onerosa que a técnica I. (tabela 5).

Se os cálculos fossem feitos somando-se ao custo dos materiais também os valores/horas dos funcionários na preparação dos pacotes e no atendimento das mulheres (tabela 3 e 4), teríamos para 6.000 coletas de urinas o valor de Cr $\$ 110.160,00$ técnica I e Cr $\$ 964.749,00$ para a técnica II. Portanto, uma economia de Cr\$854.580,00 por ano.

O emprego da técnica I permite portanto associar-se quantidade e qualidade, isto é, podese atender um maior número de pessoal, em menos tempo, mantendo-se um bom padrão de atendimento.

\section{CONCLUSÃO:}

1 - Das 50 pacientes submetidas as técnicas I e II, para colheita de urina cultura, os resultados microbiológicos, mostraram que ambas tiveram a mesma eficácia.

2 - Os tempos médios gastos para execução das técnicas I e II, foram significantemente diferentes: 8,8 minutos por pessoa para a técnica I e 19,8 minutos para a técnica II.

3 - A técnica II foi sob todos os aspectos mais onerosa que a técnica I. Um funcionário gastou em média 19 minutos no preparo do pacote na técnica II e 1,30 minutos para a técnica I.

Cada coleta de urina pela técnica II gastou Cr $\$ 97,15$ de material de consumo e para a técnica I gastou Cr $\$ 1,00$.

\begin{tabular}{|c|c|c|c|c|}
\hline \multirow{2}{*}{$\begin{array}{l}\text { Tempo em } \\
\text { Técnicas }\end{array}$} & \multicolumn{2}{|c|}{ I } & \multicolumn{2}{c|}{ II } \\
\cline { 2 - 5 } & f & $\%$ & f & $\%$ \\
\hline $5-10$ & 41 & 82,00 & - & - \\
\hline $10-15$ & 7 & 14,00 & 4 & 8,00 \\
\hline $15-20$ & 1 & 2,00 & 28 & 56,00 \\
\hline $20-25$ & - & - & 10 & 20,00 \\
\hline $25-30$ & 1 & 2,00 & 6 & 12,00 \\
\hline $30-35$ & - & - & 2 & 4,00 \\
\hline Total & 50 & 100,00 & 50 & 100,00 \\
\hline
\end{tabular}


OLIVEIRA, M.H.P. e Colaboradoras - Custo Operacional de duas Técnicas de Colheitas de Urina Cultura Bacteriológica em Mulheres num Hospital Escola. Rev. Bras. Enf.: RS, 36: 20-24 , 1983.

Tabela 2 - Montagem do ambiente para a execução das técnicas I e II no ambulatório.

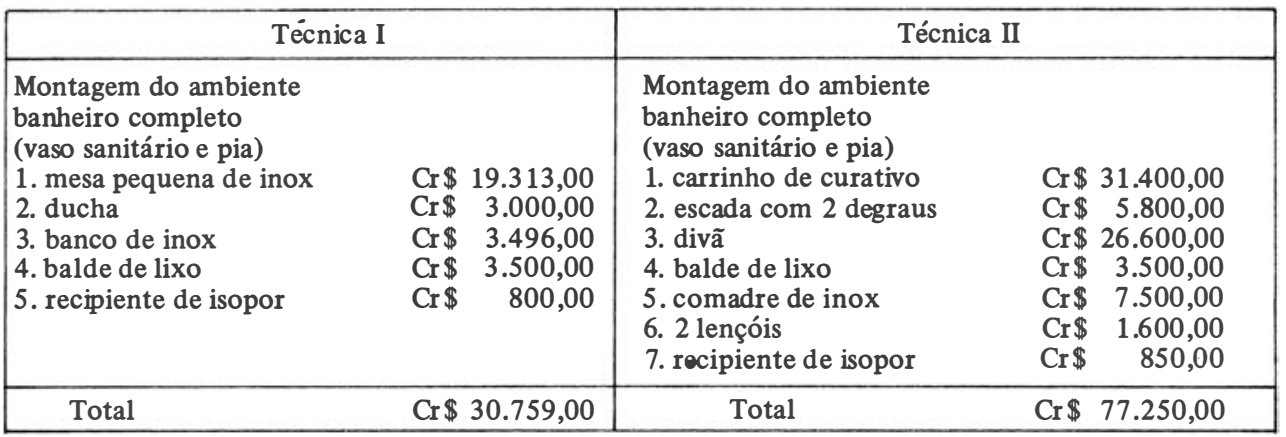

TABELA 3 - Materiais necessários para execução das técnicas I e II no ambulatório

\begin{tabular}{|c|c|c|c|c|}
\hline \multicolumn{2}{|c|}{ Técnica I } & \multicolumn{3}{|c|}{ Técnica II } \\
\hline \multicolumn{2}{|c|}{ Pacote contendo o seguinte material esterilizado: } & \multicolumn{3}{|c|}{ Paconte contendo o seguinte material esterilizado: } \\
\hline $\begin{array}{l}\text { 1. tubo de ensaio } \\
\text { 2. rolha } \\
\text { 3. uma fralda }\end{array}$ & $\begin{array}{lr}C r \$ & 42,00 \\
C r \$ & 5,00 \\
C r \$ & 120,00\end{array}$ & $\begin{array}{l}\text { 1. cuba rim } \\
\text { 2. cuba redonda } \\
\text { 3. pinça Pean } \\
\text { 4. tubo de ensaio } \\
\text { 5. rolha } \\
\text { 6. } 5 \text { gazes } \\
\text { 7. } 10 \text { bolas de algodão }\end{array}$ & $\begin{array}{l}\text { Cr\$ } \\
\text { Cr\$ } \\
\text { Cr\$ } \\
\text { Cr\$ } \\
\text { Cr\$ } \\
\text { Cr\$ } \\
\text { Cr\$ }\end{array}$ & $\begin{array}{r}600,00 \\
930,00 \\
.980,00 \\
42,00 \\
5,00 \\
13,00 \\
4,70\end{array}$ \\
\hline Sub-total & $\mathrm{Cr} \$ 167,00$ & Sub-total & $\mathrm{Cr} \$$ & $.574,50$ \\
\hline sabão neutro & 1,00 & $\begin{array}{l}1 \mathrm{par} \text { de luvas } \\
40 \mathrm{ml} \text { de sterylderm } \\
40 \mathrm{ml} \text { de soro fisiológico }\end{array}$ & $\begin{array}{l}\mathrm{Cr} \$ \\
\mathrm{Cr} \$ \\
\mathrm{Cr} \$\end{array}$ & $\begin{array}{r}60,00 \\
12,25 \\
7,50\end{array}$ \\
\hline Total & $\mathrm{Cr} \$ 168,00$ & Total & $\mathrm{Cr} \$$ & $.653,75$ \\
\hline
\end{tabular}

Tabela 4 - Tempo gasto pelo profissional *, no ambulatório para execução das técnicas I e II e seu correspodente em cruzeiros.

\begin{tabular}{|c|c|c|c|}
\hline \multicolumn{2}{|c|}{ Técnica I } & \multicolumn{2}{c|}{ Técnica II } \\
\hline 8,8 minutos & $\operatorname{Cr} \$ 15,40$ & 19,8 minutos & Cr $\$ 34,65$ \\
\hline
\end{tabular}

* Auxiliar de Enfermagem - HCRP - salário Cr\$ 25.262,00 - fevereiro de 1982.

Tabela 5 - tempo gasto, pelo profissional *, no preparo ** do pacote de material necessário para execução das técnicas I e II e seu correspondente em cruzeiros.

\begin{tabular}{|c|c|c|c|}
\hline \multicolumn{2}{|c|}{ Técnica I } & \multicolumn{2}{c|}{ Técnica II } \\
\hline 1,3 minutos & Cr\$1,96 & 19 minutos & $\operatorname{Cr} \$ 28,69$ \\
\hline
\end{tabular}

* Atendente do HCRP - salário Cr \$21.822,00 - fevereiro de 1982.

* * Preparo do material inclui a desinfecção prévia, e a montagem do pacote. 
OLIVEIRA, M.H.P. e Colaboradoras - Custo Operacional de duas Técnicas de Colheita de Urina Cultura Bacteriológica em Mulheres num Hospital Escola. Rev. Bras. Enf.: RS, 36: 20-24 , 1983.

\section{REFERENCIAS BIBLIOGRÅFICAS:}

1 - ALMEIDA, S. S. - Tratamento das infecções urinárias. Rev. Clin. Méd. 1(4): 33-48, 1967.

2 - ALMEIDA, S. S. - Diagnóstico e tratamento das infecções urinárias. Rev. Ass. Méd. Bras. (São Paulo, 9 (7-8): 254 - B, 1973.

3 - ANGERAMI, E. L. S.; SANTESSO, M.; OLIVEIRA, B.M.; BOEMER, M.R. - Avaliação da técnica de colheita de urina com assepsia-estudo em mulheres. Medicina CARL (Ribeirão Pret. S. P.) 8 (1-2): 11-14, 1976.

4 - ANGERAMI, E. L. S.; BOEMER, M. R. - Análise bacteriológica de amostras de urina coletadas com técnicas distintas. Rev. Enf. Novas Dimensões, 2 (1): 28-33, 1978.

5 - COIMBRA, M. S. R. - Infeç̧ões das vias urinárias. Atualidades Médicas. 11 (12): 20-26, 1976.

6 - DAGUET, G. L. - Técnicas em bacteriologia. I Seróbios. Barcelona. Editorial Jins. pg. 82-86, 1977.

7 - KASS, E. H. - Bacteriuria and the diagnosis of infection of the u rinary tract. Arch. intern. Med. $100,709-714,1957$.

8 - KOURANY, M. - Obtencion y manejo de muestras para examenes microbiológicos de las enfermeđades transmisibles. Puplicacions científica. 326, 38-39, 1976.

9 - KUNIN, C. M. - Infecciones urinárias - Diagnóstico, profilaxis y tratamiento. Barcelona, Toray, 1973.

10 - OLIVEIRA, M. H. P. - Levantamento de cinco hospitais da cidade de Ribeirão Preto - Dados pessoais, 1979.

11 - OLIVEIRA, M. H. P. - Levantamento em dez laboratórios particulares da ciđade de Ribeirão Preto - Dados pessoais, 1979. 